\title{
The Evidence for Hypothermia as a Neuroprotectant in Traumatic Brain Injury
}

\author{
W. Dalton Dietrich and Helen M. Bramlett \\ Department of Neurological Surgery, The Miami Project to Cure Paralysis, University of Miami Miller School of Medicine, \\ Miami, Florida 33136
}

Summary: This article reviews published experimental and clinical evidence for the benefits of modest hypothermia in the treatment of traumatic brain injury (TBI). Therapeutic hypothermia has been reported to improve outcome in several animal models of CNS injury and has been successfully translated to specific patient populations. A PubMed search for hypothermia and TBI was conducted, and important papers were selected for review. The research summarized was conducted at major academic institutions throughout the world. Experimental studies have emphasized that hypothermia can affect multiple pathophysiological mechanisms thought to participate in the detrimental consequences of TBI. Published data from sev- eral relevant clinical trials on the use of hypothermia in severely injured TBI patients are also reviewed. The consequences of mild to moderate levels of hypothermia introduced by different strategies to the head-injured patient for variable periods of time are discussed. Both experimental and clinical data support the beneficial effects of modest hypothermia following TBI in specific patient populations. Following on such single-institution studies, positive findings from multicenter TBI trials will be required before this experimental treatment can be considered standard of care. Key Words: Head trauma, hypothermia, hyperthermia, sex, pathomechanisms, pediatrics, rewarming phase, clinical trials.

\section{INTRODUCTION}

During the last 20 years, positive results have been reported in animal models of traumatic brain injury (TBI) demonstrating that modest levels of hypothermia introduced after the traumatic insult significantly improve behavioral and histological outcomes in a number of laboratory settings. ${ }^{1-9}$ Notably, some clinical studies have also reported the beneficial effects of mild to modest cooling in the head-injured patient. ${ }^{10-20}$ These positive results from multiple laboratories using different experimental models and patient populations suggest that hypothermic therapy may have a benefit in the standard care of severely head-injured patients. Nevertheless, a number of controversies remain, regarding both hypothermic efficacy and the mechanisms by which mild hypothermia may protect the brain after trauma. ${ }^{21}$ There is thus a need to continue investigation of the potentially

Address correspondence and reprint requests to: W. Dalton Dietrich, III, Ph.D., Professor of Neurological Surgery, The Miami Project to Cure Paralysis, University of Miami Miller School of Medicine, 1095 NW 14th Terrace, Suite 2-30, Miami, FL 33136-1060. E-mail: ddietrich@miami.edu. beneficial effects of hypothermia, both in experimental animal models and in patients with severe TBI.

Published experimental data on the use of cooling to protect the post-injury brain show that mild variations in brain temperature can significantly alter the pathological responses of the brain to injury. ${ }^{22-31}$ Laboratory investigations have demonstrated that brain cooling affects multiple injury cascades, including cellular and molecular events important in trauma-induced cell death and long-term functional deficits. Indeed, one of the advantages of hypothermia is that reduced temperature reduces several of the dominant injury mechanisms thought to be important in the pathophysiology of TBI.

In addition to the beneficial effects of mild reductions in temperature on traumatic outcome, recent experimental and clinical investigations have also highlighted the detrimental effects of mild hyperthermia on traumatic outcome. ${ }^{32-39}$ Experimental trauma studies first demonstrated the detrimental effects of mild hyperthermia in models of TBI, pointing to the importance of maintaining normothermia in the head-injured patient. ${ }^{32,40}$ Recently, clinical studies have also reported that patients experiencing periods of hyperthermia in the intensive care unit also demonstrate worse outcome after neurological inju- 
Table 1. Moderate Hypothermia in Rat Models of Experimental Head Trauma

\begin{tabular}{|c|c|c|c|c|}
\hline \multicolumn{3}{|c|}{ Cooling } & \multirow[b]{2}{*}{ Outcome Measures (Timing) } & \multirow[b]{2}{*}{ Reference } \\
\hline Timing & $T,{ }^{\circ} \mathrm{C}$ & Duration & & \\
\hline before + after & $36-30$ & $1 \mathrm{~h}$ & behavior ( $5 \mathrm{~d})$ & Clifton et al., ${ }^{3} 1991$ \\
\hline before + after & 30 & $1 \mathrm{~h}$ & $\mathrm{BBB}(1 \mathrm{~h})$ & Jiang et al., ${ }^{61} 1992$ \\
\hline 15, 30-min delay & 30 & $1 \mathrm{~h}$ & behavior $(5 \mathrm{~d})$ & Lyeth et al., ${ }^{7} 1993$ \\
\hline before + after & 30 & $3 \mathrm{~h}$ & MAP-2 $(3 \mathrm{~h})$ & Taft et al., ${ }^{45} 1993$ \\
\hline 5-min delay & 30 & $3 \mathrm{~h}$ & pathology $(3 \mathrm{~d})$ & Dietrich et al., ${ }^{4} 1994$ \\
\hline 3-min delay & 30 & $3 \mathrm{~h}$ & glutamate release, free radicals & Globus et al., ${ }^{26} 1995$ \\
\hline 10-min delay & 32 & $4 \mathrm{~h}$ & mortality & Clark et al., ${ }^{2} 1996$ \\
\hline 10,25 , or $40-$ min delay & 32 & $4 \mathrm{~h}$ & axonal damage & Marion and White, ${ }^{43} 1996$ \\
\hline 10-min delay & 32 & $4 \mathrm{~h}$ & inflammation & Whalen et al., ${ }^{31} 1997$ \\
\hline 5-min delay & 32 & $2 \mathrm{~h}$ & behavior (5 and $11 \mathrm{~d}$ ); pathology & Dixon et al., 1998 \\
\hline 15-min delay & 30 & $1 \mathrm{~h}$ & pathology & Yamamoto et al., ${ }^{9} 1999$ \\
\hline 30-min delay & 30 & $3 \mathrm{~h}$ & inflammation & Chatzipanteli et al., ${ }^{23} 2000$ \\
\hline immediate & 32 & $1 \mathrm{~h}$ & reactivity of microvessels & Suehiro and Povlishock, ${ }^{47} 2001$ \\
\hline $0,60,90,120-\min$ delay & 30 & $3 \mathrm{~h}$ & behavior $(24 \mathrm{~h})$ & Markgraf et al., ${ }^{8} 2001$ \\
\hline before + after & 33 & $4 \mathrm{~h}$ & TNFR1 signaling & Lotocki et al., ${ }^{29} 2006$ \\
\hline before + after & 33 & $4 \mathrm{~h}$ & ERK $1 / 2$ signaling & Atkins et al., ${ }^{25} 2007$ \\
\hline after & 32 & $4 \mathrm{~h}$ & TUNEL, caspase-3 & Jia et al., ${ }^{30} 2009$ \\
\hline
\end{tabular}

$\mathrm{BBB}=$ blood-brain barrier; ERK 1/2 = extracellular signal-regulated kinase 1/2; MAP2 = microtubule associated protein; $T=$ temperature; TNFR1 $=$ tumor necrosis factor receptor 1 ; TUNEL $=$ terminal dUTP nick end labeling.

ries. ${ }^{35,36,38,39}$ At present, no therapeutic interventions have been successfully translated to the head-injured patient that significantly improve outcome. ${ }^{41,42}$ Thus, it is important to discuss experimental treatment strategies, including therapeutic hypothermia, and to evaluate them in clinically relevant experimental models and in the clinical TBI literature.

\section{EXPERIMENTAL BRAIN TRAUMA}

Interest in the application of mild to moderate levels of brain hypothermia $\left(30-33^{\circ} \mathrm{C}\right)$ in experimental models of TBI (Table 1) occurred as a result of data in the cerebral ischemia literature showing that relatively small variations in brain temperature could critically determine the vulnerability of hippocampal neurons to a transient ischemic insult. ${ }^{22}$ In 1991, Clifton et al. ${ }^{3}$ reported that preand post-traumatic hypothermia improved beam walking in a rat model of fluid percussion brain injury. In that study, hypothermia of $30^{\circ} \mathrm{C}$ was reported to reduce overall mortality rates and to attenuate deficits in beam balance and body weight loss, compared with normothermic treatment. In another early TBI investigation, Lyeth et $\mathrm{al}^{7}$ evaluated the effect of 1 hour of post-injury hypothermia $\left(30^{\circ} \mathrm{C}\right)$ on behavioral outcome and reported evidence of improved behavioral outcome.

Whether post-traumatic hypothermia is neuroprotective in a reproducible model of TBI was first investigated by Dietrich et al., ${ }^{4}$ who in 1994 reported that post-traumatic hypothermia $\left(30^{\circ} \mathrm{C}\right)$, initiated $5 \mathrm{~min}$ after parasagittal fluid percussion brain injury, significantly reduced overall contusion volume and preserved neuronal sur- vival in pericontusional cortical areas. ${ }^{4}$ Post-traumatic hypothermia has also been tested in other models of brain injury, including controlled cortical impact injury and diffuse injury models. ${ }^{5,9}$ In a study by Dixon et al., ${ }^{5}$ post-traumatic hypothermia reduced overall contusion volume following controlled cortical impact injury. Additional animal studies have shown that post-traumatic hypothermia reduces sensorimotor and cognitive deficits, compared with normothermic animals. ${ }^{1,7}$ Because cognitive deficits are a common long-term consequence of moderate and severe TBI, this specific treatment strategy appears to improve clinically relevant outcome measures.

One of the potential limitations of any therapeutic treatment strategy being successfully translated to the clinical arena is the therapeutic window for neuroprotection. Although various pharmacological strategies have shown efficacy when administered before or immediately after the insult, few interventions have provided clinically significant protection when given in a delayed post-traumatic fashion. Thus, in terms of the treatment window for post-traumatic hypothermia, Markgraf et al. ${ }^{8}$ reported improved neurological outcome if moderate hypothermia $\left(3 \mathrm{~h}\right.$ at $\left.30^{\circ} \mathrm{C}\right)$ was initiated $60 \mathrm{~min}$ but not 90 min after controlled cortical impact injury. Although this 60- to 90-minute window would appear relatively limited when one considers the clinical situation, it is not clear how these therapeutic window results obtained in rodents directly translate to humans. Nonetheless, some optimism should be expressed based on early published clinical data showing improvements in traumatic outcomes 
in a limited number of subjects even when cooling is delayed several hours after trauma. ${ }^{13,20}$

In addition to the neuroprotective and behavioral consequences of post-traumatic hypothermia, hypothermia has also been reported to reduce the degree of diffuse axonal damage in models of TBI. ${ }^{6,43-45}$ For example, in one study, a relatively brief hypothermic period $(60 \mathrm{~min})$ administered either before injury or soon after trauma showed significant axonal protection in the major projection systems of the brain. ${ }^{6}$ For these studies, a marker of abnormal axonal transport and axonal injury, $\beta$-amyloid precursor protein ( $\beta$-APP) immunocytochemistry, was used to assess damaged axons. These investigators reported that the overall frequency of $\beta$-APP immunoreactive axonal profiles in specific white matter tracts were dramatically reduced in animals treated with early post-traumatic hypothermia. Because diffuse axonal injury may play an important role in the functional consequence of TBI, ${ }^{46}$ these findings highlight the potential usefulness of therapeutic hypothermia in the severely head-injured patient.

\section{REWARMING PHASE}

Clinical and experimental data have indicated that the rate of rewarming after a prolonged hypothermic period is critical in producing the beneficial effects of posttraumatic hypothermia. For example, in a study in which axonal pathology was targeted for hypothermic intervention, Suehiro and Povlishock ${ }^{47}$ reported an augmentation of traumatically induced axonal injury using a rapid posthypothermic rewarming protocol. In contrast, when the post-traumatic hypothermic period was followed by a slow and gradual rewarming protocol, protection of the injured axons was demonstrated. In a related study regarding the importance of the post-traumatic rewarming period, Matsushita et al. ${ }^{48}$ showed that post-traumatic hypothermia combined with a slow rewarming protocol was neuroprotective in a model of TBI complicated by a secondary hypoxic insult. Compared with normothermic TBI rats, modest hypothermia significantly reduced overall contusion volume when the post-traumatic hypothermic period was followed by slow but not rapid rewarming. The importance of the rewarming phase merits attention when considering both the experimental as well as the clinical use of modest hypothermia. In addition to the rewarming phase, other factors may also play an important role in determining the efficacy of post-traumatic hypothermia in experimental and clinical settings.

\section{THE IMPORTANCE OF SEX IN HYPOTHERMIC PROTECTION}

The sex of an animal has also been reported to influence the response of the brain to a CNS injury. ${ }^{49-52}$
Recently, the significance of sex has been demonstrated after experimental TBI, with intact female animals showing significantly smaller contusion volumes, compared with traumatized male animals of similar age. ${ }^{52}$ The role of endogenous sex hormones on this reported sex difference in traumatic vulnerability was clarified when ovariectomized rats were shown not to be protected, compared with corresponding intact females. In terms of the importance of sex in the clinical condition of TBI, both male and female patients experience the detrimental consequences of head injury, and clinical studies are now being conducted to clarify the role of sex and other factors, including ethnicity or race, in the overall vulnerability of this patient population to TBI.

Because of this sex factor in terms of TBI vulnerability, published studies have investigated whether sex may also be an important factor in whether modest hypothermia is protective after TBI. In a study by Suzuki et al., ${ }^{53}$ the importance of sex on the histopathological consequences of post-traumatic hypothermia was evaluated. Following moderate fluid percussion brain injury, posttraumatic hypothermia $\left(4 \mathrm{~h}, 33^{\circ} \mathrm{C}\right)$ was shown to significantly reduce contusion volume in ovariectomized but not intact female rats. In a related study in which the effects of sex on the detrimental consequences of posttraumatic hyperthermia were investigated, ovariectomized rats demonstrated worse outcomes, compared with intact female animals. ${ }^{54}$ Taken together, these data highlight the importance of sex in both the beneficial effects of hypothermic therapy and the detrimental consequences of secondary injury mechanisms, such as reactive hyperthermia, in the TBI patient population. Given the heterogeneous nature of the TBI population in terms of sex, age, and ethnicity or race, additional research is required to clarify how these factors may each influence outcome and therapeutic interventions, including hypothermia.

\section{MECHANISMS OF HYPOTHERMIC PROTECTION}

Brain cooling was reported in the 1960 s to decrease $\mathrm{O}_{2}$ consumption and $\mathrm{CO}_{2}$ production, as well as other indicators of metabolism. ${ }^{55,56}$ Thus, early studies emphasized that the beneficial effects of hypothermic therapy were primarily through metabolic and energy demands. Over the last few years, however, several mechanistic studies have shown that more modest levels of hypothermia have dramatic effects on multiple injury mechanisms thought to be responsible for secondary injury mechanisms. ${ }^{57}$ For example, relatively small variations in the temperature of the brain during or after an ischemic or traumatic injury alter hemodynamic events, excitotoxicity, calcium-dependent intercellular signaling, inflamma- 
tion and edema, and apoptosis, as well as molecular markers of the post-injured brain.

In the area of excitotoxicity, early studies showed that extracellular levels of the excitatory amino acid glutamate and other neurotransmitters after brain injury were reduced following mild post-traumatic hypothermia. ${ }^{26,58-60}$ Mild to moderate hypothermia was also reported to reduce abnormal blood-brain barrier permeability after both ischemic and traumatic insults. ${ }^{61-63}$ Another prominent mechanism by which hypothermia conveys cytoprotection is by reducing inflammatory processes, including trauma- induced increases in the proinflammatory cytokines interleukin- $1 \beta$ and tumor necrosis factor- $\alpha{ }^{27-29,31,64-66}$ Current research strategies include the use of temperature modifications to help dissect the critical ligand-receptor and cellular signaling events responsible for the hypothermic effect on post-traumatic inflammatory processes.

Apoptotic cell death is also involved in the vulnerability of different cell types after neurotrauma. ${ }^{67}$ Published data indicate that post-traumatic hypothermia can significantly reduce levels of caspase 3, an important initiator of apoptotic cell death and reduce cytochrome-c release from dysfunctional mitochondria. ${ }^{29}$ Other molecular mechanisms regulating these cellular events after trauma have also been recently reported to be extremely temperature sensitive. ${ }^{25,68}$ In one study, hypothermia treatment after moderate fluid percussion injury was reported to selectively reduce specific inflammatory genes thought to be important in secondary injury processes. ${ }^{68}$ Most recently, hypothermia has been shown to influence signaling cascades associated with hippocampal-dependent learning and memory, which may represent a molecular mechanism elicited by hypothermia treatment that improves functional outcome after TBI. ${ }^{25}$ Thus, study of the ability of post-traumatic temperature to affect various biochemical, molecular, and genetic responses to trauma has greatly expanded our understanding of the complexity of cell death mechanisms and the identification of novel targets for neuroprotection.

\section{CLINICAL ADULT TBI}

Profound levels of hypothermia were used in the 1960 s in several clinical centers as part of the routine treatment for severe TBI. ${ }^{69}$ In the 1970 s, however, use of hypothermia to treat TBI patients was discontinued because of serious side effects, including infectious complications and cardiovascular incidents. Also, methods for inducing hypothermia were difficult to carry out, and it was challenging to maintain a level of hypothermia using only cooling blankets and ice. New pharmacological agents, including barbiturates and later calcium channel blockers and NMDA antagonists, were also being developed and tested in head-injured patients.
In the 1990s, attention again turned to the use of hypothermia, in several clinical studies based on the encouraging findings from experimental cerebral ischemia and trauma studies. ${ }^{12,13,18,20,70,71}$ For example, in a TBI study of 82 patients, Marion et al. ${ }^{13}$ reported in 1997 that $62 \%$ of patients who underwent hypothermia treatment demonstrated good outcomes 12 months after injury, compared with $38 \%$ of those in the normothermic group. More recently, in 2000 Jiang et al. ${ }^{72}$ reported an investigation of the effects of long term (3-14 days) mild hypothermia therapy $\left(33-35^{\circ} \mathrm{C}\right)$ on outcome in 87 patients with severe TBI. Notably, the rates of complications between the normothermic and hypothermic patients were found not to be significantly different, and hypothermia markedly reduced ICP and inhibited hyperglycemia.

Another factor that may play an important role in the beneficial effects of hypothermic therapy is the duration of cooling. For example, in early cerebral ischemia studies, relatively short periods of hypothermia provided only transient protection of vulnerable neuronal populations when animals were allowed to survive weeks after the ischemic insult. ${ }^{73,74}$ In contrast, longer periods of cooling were reported to provide chronic protection and behavioral improvement. ${ }^{74}$ Thus, the importance of cooling duration has been emphasized in both preclinical and clinical TBI investigations. In this regard, Jiang et al. ${ }^{18}$ recently assessed the importance of hypothermic duration on behavioral outcome after severe TBI; in that study, TBI patients who underwent cooling for 5 days displayed better behavioral outcomes than those patients who were only cooled for a 3-day period. In future clinical trials, prolonged cooling regimens may be required to treat specific clinical cases in which shorter periods of cooling do not reduce ICP or promote clinical recovery after severe TBI.

Based on encouraging single-center studies (summarized recently by Polderman ${ }^{11}$ ), a multicenter trial was initiated by Guy Clifton to test the efficacy of modest hypothermia in a large number of severely injured patients. In that study, 392 adult patients with severe trauma were randomly selected into hypothermia versus normothermia groups. ${ }^{21}$ In contrast to several singlecenter studies of hypothermia, ${ }^{13,20}$ however, mortality rates did not differ between the two temperature groups, and no beneficial effects on outcome were reported ${ }^{21}$ (Table 2). Since this publication, several potential limitations of that original multicenter trial have been identified, including inconsistencies in patient care between sites and the delay in initiating the hypothermic therapy. $^{75}$

A recent meta-analysis of hypothermia clinical trials reported in the third edition of the guidelines for the management of severe $\mathrm{TBI}^{76}$ in 2007 included 354 patients assigned to hypothermia groups and 340 patients 
Table 2. Moderate Hypothermia in Clinical Head Trauma

\begin{tabular}{|c|c|c|c|c|}
\hline \multirow[b]{2}{*}{ Cases, no. } & \multicolumn{2}{|c|}{ Cooling } & \multirow[b]{2}{*}{ Outcome Measures } & \multirow[b]{2}{*}{ Reference } \\
\hline & $T,{ }^{\circ} \mathrm{C}$ & Duration & & \\
\hline 82 & $32-33$ & $24 \mathrm{~h}$ & improved outcome & Marion et al., ${ }^{12} 1993$ \\
\hline 46 & 33 & $48 \mathrm{~h}$ & improved outcome & Clifton et al., ${ }^{20} 1993$ \\
\hline 82 & $32-33$ & $24 \mathrm{~h}$ & hastened neurologic recovery & Marion et al., ${ }^{13} 1997$ \\
\hline 10 & $32-33$ & $24 \mathrm{~h}$ & reduced ICP & Metz et al., ${ }^{70} 1996$ \\
\hline 26 & $32-33$ & 3-4 days & improved outcome & Aibiki et al., ${ }^{77} 2000$ \\
\hline 87 & $33-35$ & 3-14 days & improved outcome & Jiang et al., ${ }^{72} 2000$ \\
\hline 392 & 33 & $48 \mathrm{~h}$ & no effect & Clifton et al., ${ }^{21} 2001$ \\
\hline 30 & 34 & $72 \mathrm{~h}$ & no effect & Gal et al., ${ }^{10} 2002$ \\
\hline 91 & 34 & $48 \mathrm{~h}$ & no effect & Shiozaki et al., ${ }^{17} 2003$ \\
\hline 396 & $32-35$ & $1-7$ days & reduced mortality, improved outcome & Zhi et al., ${ }^{19} 2003$ \\
\hline 136 & $32-34$ & $24 \mathrm{~h}$ & improved outcome & Polderman et al., ${ }^{14} 2002$ \\
\hline 215 & $33-35$ & 2 or 5 days & improved outcome & Jiang et al., ${ }^{18} 2006$ \\
\hline 80 & $33-35$ & 4 days & improved outcome & Qiu et al., ${ }^{15} 2007$ \\
\hline
\end{tabular}

$\mathrm{ICP}=$ intracranial pressure; $T=$ temperature.

assigned to normothermia groups from six clinical trials for which sufficient data was available. ${ }^{12,15,20,76,77}$ This analysis showed that hypothermia treatment was associated with a $46 \%$ increased chance of good outcome.

At present, hypothermic treatment is considered an experimental therapy and not a standard of care for patients with severe TBI. For those clinicians experienced with its use, however, it may be considered as an option for patients with refractory intracranial hypertension. Based on prospective results from the published multicenter trial on hypothermic treatment, a new hypothermia clinical trial focusing on adult patients younger than 45 with severe TBI was initiated (NCT00178711; http:// www.clinicaltrials.gov). This trial emphasizes the use of early cooling and the more consistent monitoring of patient management from the various centers. Recently, this multicenter hypothermia TBI trial was stopped based on a midstudy analysis indicating no improvement with hypothermia treatment (personal communication, Dr. Guy Clifton). Therefore, the successful translation of this experimental therapy to large numbers of TBI patients will need to be demonstrated in a large multicenter trial similar to that reported with cardiac arrest patients. ${ }^{78,79}$

\section{PEDIATRIC TBI}

As already noted, age appears to be another critical factor in determining whether hypothermic therapy is protective. Thus, the potential beneficial effects of modest hypothermia have been evaluated in the pediatric trauma population. As with adult hypothermia, results from some preclinical data support the concept that modest hypothermia may be protective in models of pediatric TBI. ${ }^{80}$ Based on these findings, clinical studies have been initiated to test the efficacy of therapeutic hypothermia in the pediatric TBI population..$^{81-83}$ The use of temperature regulation and hypothermic therapy in small numbers of patients provided encouraging results. However, a recently published phase III multicenter international study with the use of moderate hypothermia $\left(32.5^{\circ} \mathrm{C}, 24 \mathrm{~h}\right)$ initiated within 8 hours in children and adolescents with severe TBI was negative. ${ }^{83}$ Recent discussions have again indicated potential shortcomings of that clinical trial, including a delay in cooling, critical care management issues as well as the rewarming procedure. As with adult TBI, additional studies are now required to determine the efficacy of this experimental treatment in the pediatric patient population.

\section{CONCLUSIONS}

Progress has been made recently on the use of mild to moderate levels of hypothermia in both experimental and clinical TBI studies. These investigations have provided a solid foundation for evaluating hypothermic strategies in the TBI patient population. It is clear from both the positive and negative findings with hypothermic therapy that various factors, not necessarily currently understood, may determine traumatic outcomes. Factors including appropriate patient populations, injury severity, age, sex, and clinical management appear to play a major role in determining the efficacy of this complex yet exciting treatment paradigm. Critical questions also remain regarding the therapeutic window of hypothermic treatment, how long cooling should be continued in specific patient populations, as well as rewarming phase factors. Although single-site hypothermia studies have demonstrated safety as well as some degree of efficacy with modest hypothermia treatment in limited patient populations, multicenter phase III trials have failed to demonstrate a benefit in either the adult or the pediatric TBI population. 
Hypothermic TBI treatment remains experimental and additional experimental and clinical studies must continue to evaluate how best to use this treatment strategy in the severe TBI patient. Studies are also required to evaluate and determine what specific cooling devices work best for the TBI population and how best to inhibit periods of reactive hyperthermia. In addition, combination approaches are currently being discussed in the trauma field, and therefore it will be important to determine what pharmacological agents can be combined with mild cooling with the goal of producing synergistic benefits to the patient. The successful translation of therapeutic hypothermia to the general TBI patient population will be achieved only through continued investigations of this potentially important therapy, including the design of well-controlled clinical trials.

Acknowledgments: This work was supported by National Institutes of Health-National Institute of Neurological Disorders and Stroke grants NS030291 and NS042133.

\section{REFERENCES}

1. Bramlett HM, Green EJ, Dietrich WD, Busto R, Globus MY, Ginsberg MD. Posttraumatic brain hypothermia provides protection from sensorimotor and cognitive behavioral deficits. J Neurotrauma 1995;12:289-298.

2. Clark RS, Kochanek PM, Marion DW, et al. Mild posttraumatic hypothermia reduces mortality after severe controlled cortical impact in rats. J Cereb Blood Flow Metab 1996;16:253-261.

3. Clifton GL, Jiang JY, Lyeth BG, Jenkins LW, Hamm RJ, Hayes RL. Marked protection by moderate hypothermia after experimental traumatic brain injury. J Cereb Blood Flow Metab 1991;11: 114-121.

4. Dietrich WD, Alonso O, Busto R, Globus MY, Ginsberg MD. Post-traumatic brain hypothermia reduces histopathological damage following concussive brain injury in the rat. Acta Neuropathol 1994;87:250-258.

5. Dixon CE, Markgraf CG, Angileri F, et al. Protective effects of moderate hypothermia on behavioral deficits but not necrotic cavitation following cortical impact injury in the rat. J Neurotrauma 1998;15:95-103.

6. Koizumi H, Povlishock JT. Posttraumatic hypothermia in the treatment of axonal damage in an animal model of traumatic axonal injury. J Neurosurg 1998;89:303-309.

7. Lyeth BG, Jiang JY, Liu S. Behavioral protection by moderate hypothermia initiated after experimental traumatic brain injury. J Neurotrauma 1993;10:57-64.

8. Markgraf CG, Clifton GL, Moody MR. Treatment window for hypothermia in brain injury. J Neurosurg 2001;95:979-983.

9. Yamamoto M, Marmarou CR, Stiefel MF, Beaumont A, Marmarou A. Neuroprotective effect of hypothermia on neuronal injury in diffuse traumatic brain injury coupled with hypoxia and hypotension. J Neurotrauma 1999;16:487-500.

10. Gal R, Cundrle I, Zimova I, Smrcka M. Mild hypothermia therapy for patients with severe brain injury. Clin Neurol Neurosurg 2002; 104:318-321.

11. Polderman KH. Induced hypothermia and fever control for prevention and treatment of neurological injuries. Lancet 2008;371: 1955-1969.

12. Marion DW, Obrist WD, Carlier PM, Penrod LE, Darby JM. The use of moderate therapeutic hypothermia for patients with severe head injuries: a preliminary report. J Neurosurg 1993;79:354-362.

13. Marion DW, Penrod LE, Kelsey SF, et al. Treatment of traumatic brain injury with moderate hypothermia. N Engl J Med 1997;336: $540-546$.
14. Polderman KH, Tjong Tjin Joe R, Peerdeman SM, Vandertop WP, Girbes AR. Effects of therapeutic hypothermia on intracranial pressure and outcome in patients with severe head injury. Intensive Care Med 2002;28:1563-1573.

15. Qiu W, Zhang Y, Sheng H, et al. Effects of therapeutic mild hypothermia on patients with severe traumatic brain injury after craniotomy. J Crit Care 2007;22:229-235.

16. Qiu WS, Liu WG, Shen H, et al. Therapeutic effect of mild hypothermia on severe traumatic head injury. Chin J Traumatol 2005;8:27-32.

17. Shiozaki T, Nakajima Y, Taneda M, et al. Efficacy of moderate hypothermia in patients with severe head injury and intracranial hypertension refractory to mild hypothermia. J Neurosurg 2003; 99:47-51.

18. Jiang JY, Xu W, Li WP, et al. Effect of long-term mild hypothermia or short-term mild hypothermia on outcome of patients with severe traumatic brain injury. J Cereb Blood Flow Metab 2006; 26:771-776.

19. Zhi D, Zhang S, Lin X. Study on therapeutic mechanism and clinical effect of mild hypothermia in patients with severe head injury. Surg Neurol 2003;59:381-385.

20. Clifton GL, Allen S, Barrodale P, et al. A phase II study of moderate hypothermia in severe brain injury. J Neurotrauma 1993; 10:263-271.

21. Clifton GL, Miller ER, Choi SC, et al. Lack of effect of induction of hypothermia after acute brain injury. N Engl J Med 2001;344: 556-563.

22. Busto R, Dietrich WD, Globus MY, Valdés I, Scheinberg P, Ginsberg MD. Small differences in intraischemic brain temperature critically determine the extent of ischemic neuronal injury. J Cereb Blood Flow Metab 1987;7:729-738.

23. Chatzipanteli K, Alonso OF, Kraydieh S, Dietrich WD. Importance of posttraumatic hypothermia and hyperthermia on the inflammatory response after fluid percussion brain injury: biochemical and immunocytochemical studies. J Cereb Blood Flow Metab 2000; 20:531-542.

24. Büki A, Koizumi H, Povlishock JT. Moderate posttraumatic hypothermia decreases early calpain-mediated proteolysis and concomitant cytoskeletal compromise in traumatic axonal injury. Exp Neurol 1999;159:319-328.

25. Atkins CM, Oliva AA Jr, Alonso OF, et al. Hypothermia treatment potentiates ERK1/2 activation after traumatic brain injury. Eur J Neurosci 2007;26:810-819.

26. Globus MY, Alonso O, Dietrich WD, Busto R, Ginsberg MD Glutamate release and free radical production following brain injury: effects of posttraumatic hypothermia. J Neurochem 1995;65: $1704-1711$.

27. Goss JR, Styren SD, Miller PD, et al. Hypothermia attenuates the normal increase in interleukin $1 \beta$ RNA and nerve growth factor following traumatic brain injury in the rat. J Neurotrauma 1995; 12:159-167.

28. Kinoshita K, Chatzipanteli K, Vitarbo E, Truettner JS, Alonso OF, Dietrich WD. Interleukin- $1 \beta$ messenger ribonucleic acid and protein levels after fluid-percussion brain injury in rats: importance of injury severity and brain temperature. Neurosurgery 2002;51:195203.

29. Lotocki G, de Rivero Vaccari JP, Perez ER, et al. Therapeutic hypothermia modulates TNFR1 signaling in the traumatized brain via early transient activation of the JNK pathway and suppression of XIAP cleavage. Eur J Neurosci 2006;24:2283-2290.

30. Jia F, Mao Q, Liang YM, Jiang JY. Effect of post-traumatic mild hypothermia on hippocampal cell death after traumatic brain injury in rats. J Neurotrauma 2009;26:243-252.

31. Whalen MJ, Carlos TM, Clark RS, et al. The effect of brain temperature on acute inflammation after traumatic brain injury in rats. J Neurotrauma 1997;14:561-572.

32. Dietrich WD, Alonso O, Halley M, Busto R. Delayed posttraumatic brain hyperthermia worsens outcome after fluid percussion brain injury: a light and electron microscopic study in rats. Neurosurgery 1996;38:533-541.

33. Verlooy J, Heytens L, Veeckmans G, Selosse P. Intracerebral temperature monitoring in severely head injured patients. Acta Neurochir (Wien) 1995;134:76-78. 
34. Cairns CJ, Andrews PJ. Management of hyperthermia in traumatic brain injury. Curr Opin Crit Care 2002;8:106-110.

35. Diringer MN, Reaven NL, Funk SE, Uman GC. Elevated body temperature independently contributes to increased length of stay in neurologic intensive care unit patients [Erratum in: Crit Care Med 2004;32:2170]. Crit Care Med 2004;32:1489-1495.

36. Oliveira-Filho J, Ezzeddine MA, Segal AZ, et al. Fever in subarachnoid hemorrhage: relationship to vasospasm and outcome. Neurology 2001;56:1299-1304.

37. Thompson HJ, Hoover RC, Tkacs NC, Saatman KE, McIntosh TK. Development of posttraumatic hyperthermia after traumatic brain injury in rats is associated with increased periventricular inflammation. J Cereb Blood Flow Metab 2005;25:163-176.

38. Fernandez A, Schmidt JM, Claassen J, et al. Fever after subarachnoid hemorrhage: risk factors and impact on outcome. Neurology 2007;68:1013-1019.

39. Kilpatrick MM, Lowry DW, Firlik AD, Yonas H, Marion DW. Hyperthermia in the neurosurgical intensive care unit. Neurosurgery 2000;47:850-855.

40. Dietrich WD, Bramlett HM. Hyperthermia and central nervous system injury. Prog Brain Res 2007;162:201-217.

41. Marklund N, Bakshi A, Castelbuono DJ, Conte V, McIntosh TK. Evaluation of pharmacological treatment strategies in traumatic brain injury. Curr Pharm Des 2006;12:1645-1680.

42. Narayan RK, Michel ME, Ansell B, et al. Clinical trials in head injury. J Neurotrauma 2002;19:503-557.

43. Marion DW, White MJ. Treatment of experimental brain injury with moderate hypothermia and 21-aminosteroids. J Neurotrauma 1996;13:139-147.

44. Maxwell WL, Donnelly S, Sun X, Fenton T, Puri N, Graham DI. Axonal cytoskeletal responses to nondisruptive axonal injury and the short-term effects of posttraumatic hypothermia. J Neurotrauma 1999;16:1225-1234.

45. Taft WC, Yang K, Dixon CE, et al. Hypothermia attenuates the loss of hippocampal microtubule-associated protein 2 (MAP2) following traumatic brain injury. J Cereb Blood Flow Metab 1993; 13:796-802.

46. Povlishock JT. Traumatically induced axonal injury: pathogenesis and pathobiological implications. Brain Pathol 1992;2:1-12.

47. Suehiro E, Povlishock JT. Exacerbation of traumatically induced axonal injury by rapid posthypothermic rewarming and attenuation of axonal change by cyclosporin A. J Neurosurg 2001;94:493498.

48. Matsushita Y, Bramlett HM, Alonso O, Dietrich WD. Posttraumatic hypothermia is neuroprotective in a model of traumatic brain injury complicated by a secondary hypoxic insult. Crit Care Med 2001;29:2060-2066.

49. Hurn PD, Macrae IM. Estrogen as a neuroprotectant in stroke. J Cereb Blood Flow Metab 2000;20:631-652.

50. Roof RL, Hall ED. Estrogen-related gender difference in survival rate and cortical blood flow after impact-acceleration head injury in rats. J Neurotrauma 2000;17:1155-1169.

51. Stein DG. Brain damage, sex hormones and recovery: a new role for progesterone and estrogen? Trends Neurosci 2001;24:386-391.

52. Bramlett HM, Dietrich WD. Neuropathological protection after traumatic brain injury in intact female rats versus males or ovariectomized females. J Neurotrauma 2001;18:891-900.

53. Suzuki T, Bramlett HM, Dietrich WD. The importance of gender on the beneficial effects of posttraumatic hypothermia. Exp Neurol 2003;184:1017-1026.

54. Suzuki T, Bramlett HM, Ruenes G, Dietrich WD. The effects of early post-traumatic hyperthermia in female and ovariectomized rats. J Neurotrauma 2004;21:842-853.

55. Rosomoff HL. The effects of hypothermia on the physiology of the nervous system. Surgery 1956;40:328-336.

56. Rosomoff HL. Cerebral blood flow and cerebral oxygen consumption during hypothermia. Am J Physiol 1954;179:85-88.

57. Dietrich WD. The importance of brain temperature in cerebral injury. J Neurotrauma 1992;9 Suppl 2:S475-S485.

58. Jiang JY, Liang YM, Luo QZ, Zhu C. Effect of mild hypothermia on brain dialysate lactate after fluid percussion brain injury in rodents. Neurosurgery 2004;54:713-717.
59. Lyeth BG, Jiang JY, Robinson SE, Guo H, Jenkins LW. Hypothermia blunts acetylcholine increase in CSF of traumatically brain injured rats. Mol Chem Neuropathol 1993;18:247-256.

60. Koizumi H, Fujisawa H, Ito H, Maekawa T, Di X, Bullock R. Effects of mild hypothermia on cerebral blood flow-independent changes in cortical extracellular levels of amino acids following contusion trauma in the rat. Brain Res 1997;747:304-312.

61. Jiang JY, Lyeth BG, Kapasi MZ, Jenkins LW, Povlishock JT. Moderate hypothermia reduces blood-brain barrier disruption following traumatic brain injury in the rat. Acta Neuropathol 1992; 84:495-500.

62. Kinoshita K, Chatzipanteli K, Alonso OF, Howard M, Dietrich WD. The effect of brain temperature on hemoglobin extravasation after traumatic brain injury. J Neurosurg 2002;97:945-953.

63. Arican N, Kaya M, Yorulmaz C, et al. Effect of hypothermia on blood-brain barrier permeability following traumatic brain injury in chronically ethanol-treated rats. Int J Neurosci 2006;116:12491261.

64. Chatzipanteli K, Wada K, Busto R, Dietrich WD. Effects of moderate hypothermia on constitutive and inducible nitric oxide synthase activities after traumatic brain injury in the rat. J Neurochem 1999;72:2047-2052.

65. Vitarbo EA, Chatzipanteli K, Kinoshita K, Truettner JS, Alonso OF, Dietrich WD. Tumor necrosis factor $\alpha$ expression and protein levels after fluid percussion injury in rats: the effect of injury severity and brain temperature. Neurosurgery 2004;55:416-424.

66. Truettner JS, Alonso OF, Dietrich DW. Influence of therapeutic hypothermia on matrix metalloproteinase activity after traumatic brain injury in rats. J Cereb Blood Flow Metab 2005;25:15051516.

67. Keane RW, Kraydieh S, Lotocki G, Alonso OF, Aldana P, Dietrich WD. Apoptotic and antiapoptotic mechanisms after traumatic brain injury. J Cereb Blood Flow Metab 2001;21:1189-1198.

68. Truettner JS, Suzuki T, Dietrich WD. The effect of therapeutic hypothermia on the expression of inflammatory response genes following moderate traumatic brain injury in the rat. Brain Res Mol Brain Res 2005;138:124-134.

69. Sedzimir CB. Therapeutic hypothermia in cases of head injury. J Neurosurg 1959;16:407-414.

70. Metz C, Holzschuh M, Bein T, et al. Moderate hypothermia in patients with severe head injury: cerebral and extracerebral effects. J Neurosurg 1996;85:533-541.

71. Tateishi A, Soejima Y, Taira Y, et al. Feasibility of the titration method of mild hypothermia in severely head-injured patients with intracranial hypertension. Neurosurgery 1998;42:1065-1069.

72. Jiang J, Yu M, Zhu C. Effect of long-term mild hypothermia therapy in patients with severe traumatic brain injury: 1-year follow-up review of 87 cases. J Neurosurg 2000;93:546-549.

73. Dietrich WD, Busto R, Alonso O, Globus MY, Ginsberg MD. Intraischemic but not postischemic brain hypothermia protects chronically following global forebrain ischemia in rats. J Cereb Blood Flow Metab 1993;13:541-549.

74. Colbourne F, Corbett D. Delayed postischemic hypothermia: a six month survival study using behavioral and histological assessments of neuroprotection. J Neurosci 1995;15:7250-7260.

75. Clifton GL, Choi SC, Miller ER, et al. Intercenter variance in clinical trials of head trauma-experience of the National Acute Brain Injury Study: Hypothermia. J Neurosurg 2001;95:751-755.

76. Brain Trauma Foundation; American Association of Neurological Surgeons; Congress of Neurological Surgeons; Joint Section on Neurotrauma and Critical Care, AANS/CNS; Bratton SL, Chestnut RM, Ghajar J, et al. Guidelines for the management of severe traumatic brain injury. III. Prophylactic hypothermia. J Neurotrauma 2007;24 Suppl 1:S21-S25.

77. Aibiki M, Maekawa S, Yokono S. Moderate hypothermia improves imbalances of thromboxane $\mathrm{A}_{2}$ and prostaglandin $\mathrm{I}_{2}$ production after traumatic brain injury in humans. Crit Care Med 2000;28:3902-3906.

78. Bernard SA, Gray TW, Buist MD, et al. Treatment of comatose survivors of out-of-hospital cardiac arrest with induced hypothermia. N Engl J Med 2002;346:557-563. 
79. Polderman KH, Rijnsburger ER, Peerdeman SM, Girbes AR. Induction of hypothermia in patients with various types of neurologic injury with use of large volumes of ice-cold intravenous fluid. Crit Care Med 2005;33:2744-2751.

80. Mansfield RT, Schiding JK, Hamilton RL, Kochanek PM. Effects of hypothermia on traumatic brain injury in immature rats. J Cereb Blood Flow Metab 1996;16:244-252.

81. Biswas AK, Bruce DA, Sklar FH, Bokovoy JL, Sommerauer JF. Treatment of acute traumatic brain injury in children with moder- ate hypothermia improves intracranial hypertension. Crit Care Med 2002;30:2742-2751.

82. Adelson PD, Ragheb J, Kanev P, et al. Phase II clinical trial of moderate hypothermia after severe traumatic brain injury in children. Neurosurgery 2005;56:740-754.

83. Hutchison JS, Ward RE, Lacroix J, et al.; Hypothermia Pediatric Head Injury Trial Investigators and the Canadian Critical Care Trials Group. Hypothermia therapy after traumatic brain injury in children. N Engl J Med 2008;358:2447-2456. 